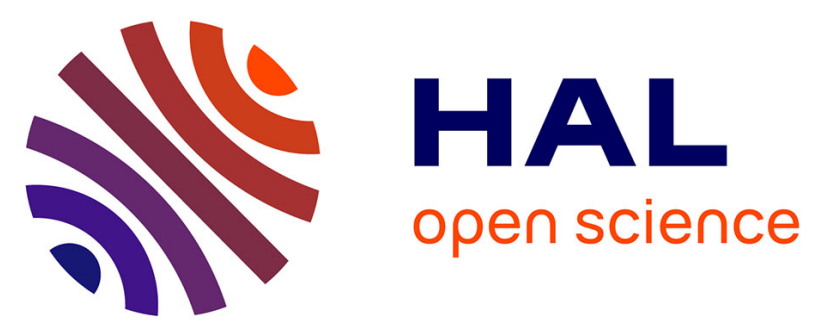

\title{
Performance of Image Correlation Techniques for Landslide Displacement Monitoring
}

Julien Travelletti, Christophe Delacourt, Jean-Philippe Malet, Pascal

Allemand, Jean Schmittbuhl, Renaud Toussaint

\section{> To cite this version:}

Julien Travelletti, Christophe Delacourt, Jean-Philippe Malet, Pascal Allemand, Jean Schmittbuhl, et al.. Performance of Image Correlation Techniques for Landslide Displacement Monitoring. Landslide Science and Practice, Margottini C., Canuti P., Sassa K. (eds) Springer, pp.217-226, 2013, 978-3-64231444-5. 10.1007/978-3-642-31445-2_28. hal-02130589

\section{HAL Id: hal-02130589 \\ https://hal.science/hal-02130589}

Submitted on 15 May 2019

HAL is a multi-disciplinary open access archive for the deposit and dissemination of scientific research documents, whether they are published or not. The documents may come from teaching and research institutions in France or abroad, or from public or private research centers.
L'archive ouverte pluridisciplinaire HAL, est destinée au dépôt et à la diffusion de documents scientifiques de niveau recherche, publiés ou non, émanant des établissements d'enseignement et de recherche français ou étrangers, des laboratoires publics ou privés. 


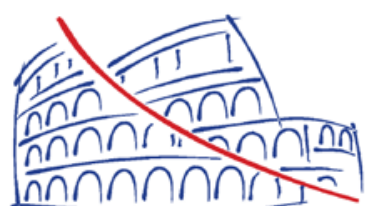

TIHE SECOND

WORLD

LANDSLIDE FORUM

Julien Travelletti ${ }^{(1)}$, Christophe Delacourt ${ }^{(2)}$, Jean-Philippe Malet ${ }^{(1)}$, Pascal Allemand $^{(3)}$, Jean Schmittbuhl ${ }^{(1)}$, Renaud Toussaint ${ }^{(1)}$

\title{
Performance of image correlation techniques for landslide displacement monitoring
}

\author{
(1) Institut de Physique du Globe de Strasbourg, CNRS UMR 7516, Université de \\ Strasbourg, Ecole et Observatoire des Sciences de la Terre, 5 rue Descartes, F-67084 \\ Strasbourg, France. Email: jeanphilippe.malet@unistra.fr \\ (2) Laboratoire Domaines Océaniques, CNRS UMR 6538, Université de Bretagne \\ Occidentale, Institut Universitaire Européen de la Mer, Rue Dumont d'Urville, F-29280 \\ Plouzané, France. \\ (3) Laboratoire de Géologie de Lyon - Terre, Planète, Environnement, CNRS UMR 5276, \\ Université de Lyon 1 et Ecole Normale Supérieure de Lyon, 2 rue Raphaël Dubois, F- \\ 69622 Villeurbanne Cedex, France.
}

\begin{abstract}
The objective of this work is to present the applicability of image correlation techniques (applied to very-high resolution terrestrial optical photographs and to very dense Terrestrial Laser Scanning (TLS) point clouds) to monitor the displacement of continuously active landslides. The method has been developed to characterize the kinematics of very active landslides with cumulated displacement of several decimeters per year. The monitoring system consists in a high resolution optical camera installed on a concrete pillar located on a stable crest in front of the Super-Sauze landslide (South East French Alps) and on repeated TLS acquisitions over the period 2008-2009. The data are processed with a cross-correlation algorithm applied on the full resolution images (photographs and DEMs produced from the TLS data) in the acquisition geometry. Then, the calculated $2 \mathrm{D}$ displacement field is ortho-rectified with a back projection technique. The method allows to characterize the heterogeneous displacement field of the landslide in time and space, and to produce displacement maps. The performance of the technique is assessed using as reference differential GPS surveys of a series of benchmarks.

The sources of error affecting the results are discussed. Because the proposed methodology can be routinely and automatically applied, it offers promising perspectives for operational applications like, for instance, in early warning systems.
\end{abstract}

Keywords image cross-correlation; image matching; time-lapse acquisition; displacement monitoring; LiDAR, landslide

\section{Introduction}

Displacement monitoring of unstable slopes is a crucial tool for the prevention of hazards. It is often the only solution for the survey and the early-warning of large landslides that cannot be stabilized or that may accelerate suddenly. The choice of an adequate monitoring system depends on the landslide type and size, the range of observed velocity, the required frequency of acquisition, the desired accuracy and the financial constraints. Displacement monitoring techniques applied on landslides can be broadly subdivided in two main groups: geodetic and remotesensing techniques.

Geodetic surveying consist in detecting geometrical changes in the landslide topography by measuring geometric parameters such as angles, distances or differences in elevation (e.g. levelling, tacheometry). These techniques necessitate the installation of targets in and outside the landslide and in measuring their position at different times. They have the advantage to be very accurate $(0.2$ to $2.0 \mathrm{~cm})$ with a high potential of automation (Malet et al., 2002; Jaboyedoff et al., 2004; Foppe et al., 2006). However, because landslides can show highly variable displacement rates in time and space according to the local slope conditions (bedrock geometry, distribution of pore water pressures), the major drawbacks of the geodetic techniques are (1) to provide only discrete point measurements of the displacement and (2) the costs of installation and maintenance of the survey network.

Remote-sensing techniques are interesting tools to obtain spatially-distributed information on the kinematics (Delacourt et al., 2007) and can be operational from spaceborne, airborne and ground-based platforms. Remote-sensing techniques give the possibility to discriminate stable and unstable areas and to map sectors within the landslide with different kinematics from a regional to a local scale (Casson et al., 2005; Teza et al., 2008; Oppikofer et al., 2008). Three main categories of remote sensing techniques, either operated from terrestrial or airborne platforms, are used in landslide monitoring: Synthetic Aperture Radar Interferometry (InSAR), Laser Scanning (LiDAR) and Optical Photogrammetry (OP).

The objective of this work is to highlight the possible applications and limitations of cross-correlation techniques applied both on airborne and terrestrial LiDAR point clouds and on very-high resolution optical 
images. Several datasets of multi-source images acquired on the La Valette and Super-Sauze landslides (South French Alps) over the period 2007-2010 from different platforms are analysed. The influence of external factors on the precision and the accuracy of the results are discussed. Throughout this work, the accuracy is defined as the systematic difference between a measured quantity and the true value, and precision is defined as the random difference between multiple measurements of the same quantity.

\section{Principle of the Image Correlation technique}

Using matching techniques, two-dimensional displacement fields can be derived by tracking objects in two images acquired at different time. The technique is based on the automatic identification of identical texture patterns within an image by maximizing a correlation function (Lewis, 1995). Its principle adapted for landslide kinematics analysis is described in Delacourt et al. (2007).

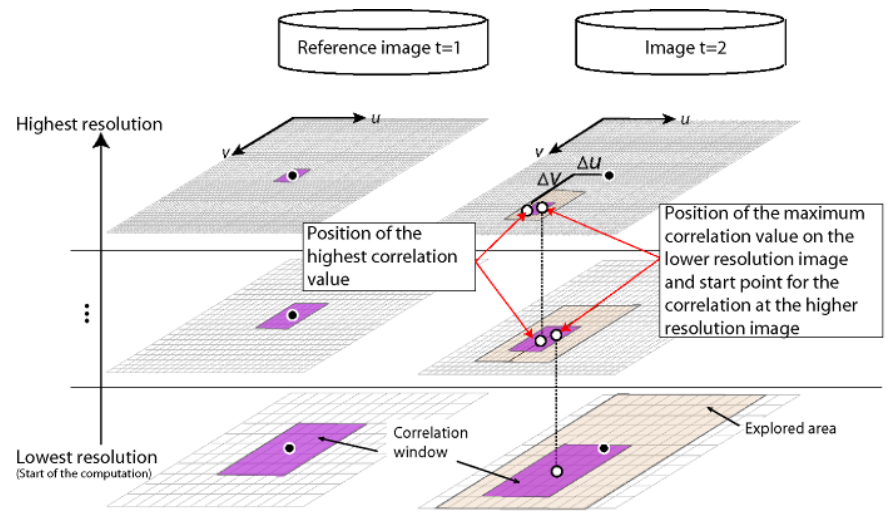

Figure 1 Principle of the normalized hierarchical image correlation technique.

Visible ground features have to be superimposed on two successive images on stable parts located outside the landslide. On the areas affected by landslide movements, the visible and recognizable features are shifted by the displacements. In order to quantify the ground displacements, a correlation window is defined on a reference (often the oldest) image. The corresponding window is searched in a pre-defined explored area belonging to the second image (Fig. 1). The starting point of this explored area is the expected position of the window with the assumption that no displacement occurred between two acquisitions. The process is repeated for each pixel of the reference image. The Euclidean distance between the reference point and the matching point represents the displacement amplitudes in the image plane. By modifying the zone of interest, it is then possible to determine the displacements at various positions within the images. It is important to note that the normalized cross-correlation technique cannot track objects that start to rotate significantly or are affected by important perspective distortions (Lewis, 1995).
The size of the correlation window is a compromise between the desired accuracy on the displacement estimates and the spatial resolution of the velocity field (Delacourt et al., 2007). An increase of the size of the correlation window ensures a good signal to noise ratio and thus a good precision, but the accuracy on the displacement estimates decreases because of their averaging on a larger correlation window. This compromise is difficult to define when some parts of the landslide are well represented in terms of ground texture while others parts are not. Hierarchical correlation techniques allow one to overcome this problem by automatically changing the physical size of the correlation window and of the explored area during the correlation computations. The physical size is defined as the effective landslide surface covered by the correlation window (Rohaly, 2002; Aloui \& Ibn-Elhaj, 2009).

So far, Image Correlation techniques have been applied only on aerial and satellite images (e.g. SPOT, QuickBird, OrbView, EROS) for the creation of landslide displacement maps (Casson et al., 2003; Delacourt et al., 2004; LePrince et al., 2008; Debella-Gilo \& Kääb, 2010).

\section{Characteristics of the hierarchical cross-correlation technique used in this work}

In this work, a sub-pixel hierarchical correlation technique is used (Hild, 2003). The original images are first converted in gray-scale images on which a $3 \times 3$ pixel Sobel convolution matrix is applied to highlight the ground surface texture. The gradient values are then correlated (Chambon, 2003). Four successive degradations of the image resolution are applied following a pyramidal approach for changing the physical size of the correlation window and of the explored area by down-sampling the gradient values of the full resolution image (Kumar \& Banerjee, 1998) (Fig. 1). The optimum sizes of the correlation window and of the explored area are identified with a trial and error procedure. The correlation starts with the lowest resolution image in order to determine the largest displacements. Then the location of the pixel with the maximum cross-correlation value is used as the centre of the zone of interest for the next correlation step at a higher resolution. The spatial location of the maximum correlation value in the highest resolution image is thus progressively better estimated (Fig. 1). Ignoring high resolution information at the first computational step decreases the probability to reach a local minimum of the correlation function and, consequently, to obtain a wrong matching in the correspondence solution (Aloui \& IbnElhaj, 2009). In addition, this approach ensures very often a higher probability of detecting a reliable correlation peak. The sub-pixel displacement is computed after the correlation at the highest resolution image. An iterative procedure is used to find the maxima of the correlation function interpolated with a bi-parabolic formula and 
with a maximization procedure based on the simplex method (Press et al., 1997).

The correlation results consist in matrices of displacement $\Delta u$ and $\Delta v$ along the $u$ - and $v$-axes in the image plane with their associated correlation index (Fig. 1). In case of orthorectified airborne images, the pixel size is constant, only the effective pixel size at the ground has to be calculated to estimate metric displacements. In case of terrestrial images, the pixel size is not constant in the image due to the oblique acquisition; the displacements field correlated in the image plane cannot be directly interpreted in terms of metric displacements and an orthorectification procedure is compulsory for a quantitative analysis.

\section{Application 1: Image Correlation of terrestrial photographs}

A set of images acquired at the Super-Sauze landslide over the period May-July 2008 is used to illustrate the potential of the technique for the characterization of the kinematics during an acceleration period (Travelletti et al., in press).
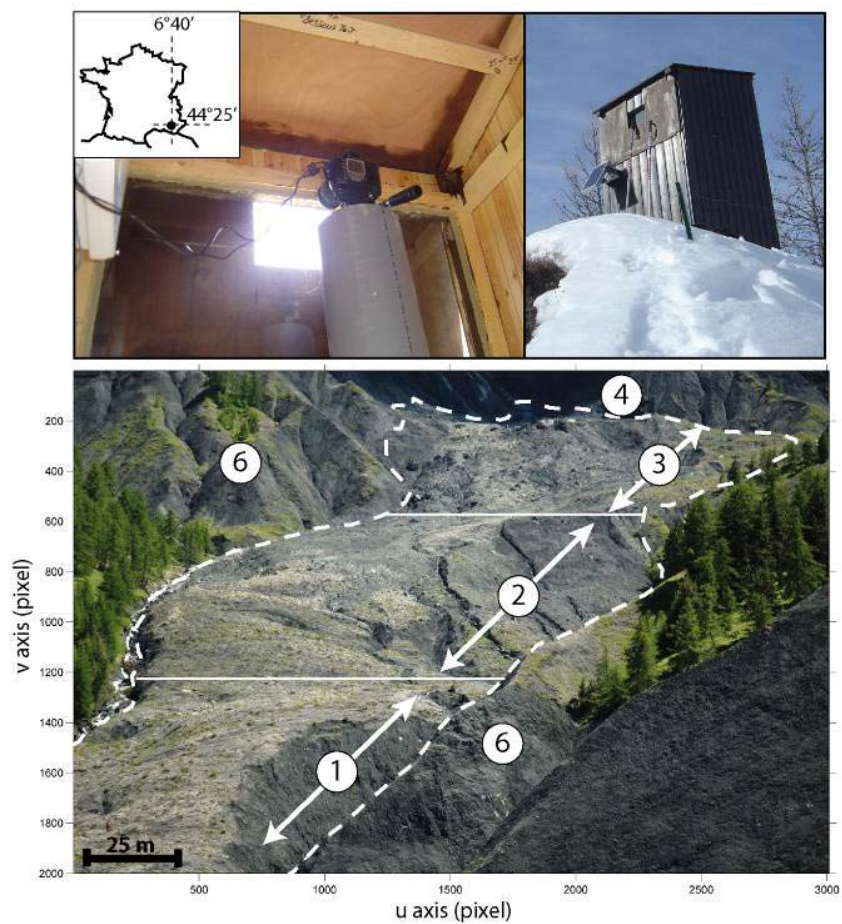

Figure 2 Monitoring system with a very-high resolution camera installed in front of the Super-Sauze landslide on a stable crest. Top: Monitoring system. Bottom: Image acquired by the monitoring system presenting the different parts of the landslide from the camera location. The numbers refers to: (1): Lower part (toe) of the landslide, (2) Middle part (transition zone), (3) Upper part (abalation zone), (4) Main scarp (1980 m), (5) Front (1734 m), (6) Stable crests.

Figure 2 presents the monitoring system installed in front of the landslide. The instrumentation consists in a low-cost D70 Nikon reflex digital camera installed on a concrete pillar located at a distance of $300 \mathrm{~m}$ from the lower part and $900 \mathrm{~m}$ from the main scarp (Fig. 2A, B). The acquisition system is controlled by a datalogger and the power is provided by a $40 \mathrm{~W}$ solar panel. Every four days, a serie of images is acquired at 11:00, 12:00, 13:00 and 14:Oo GMT.

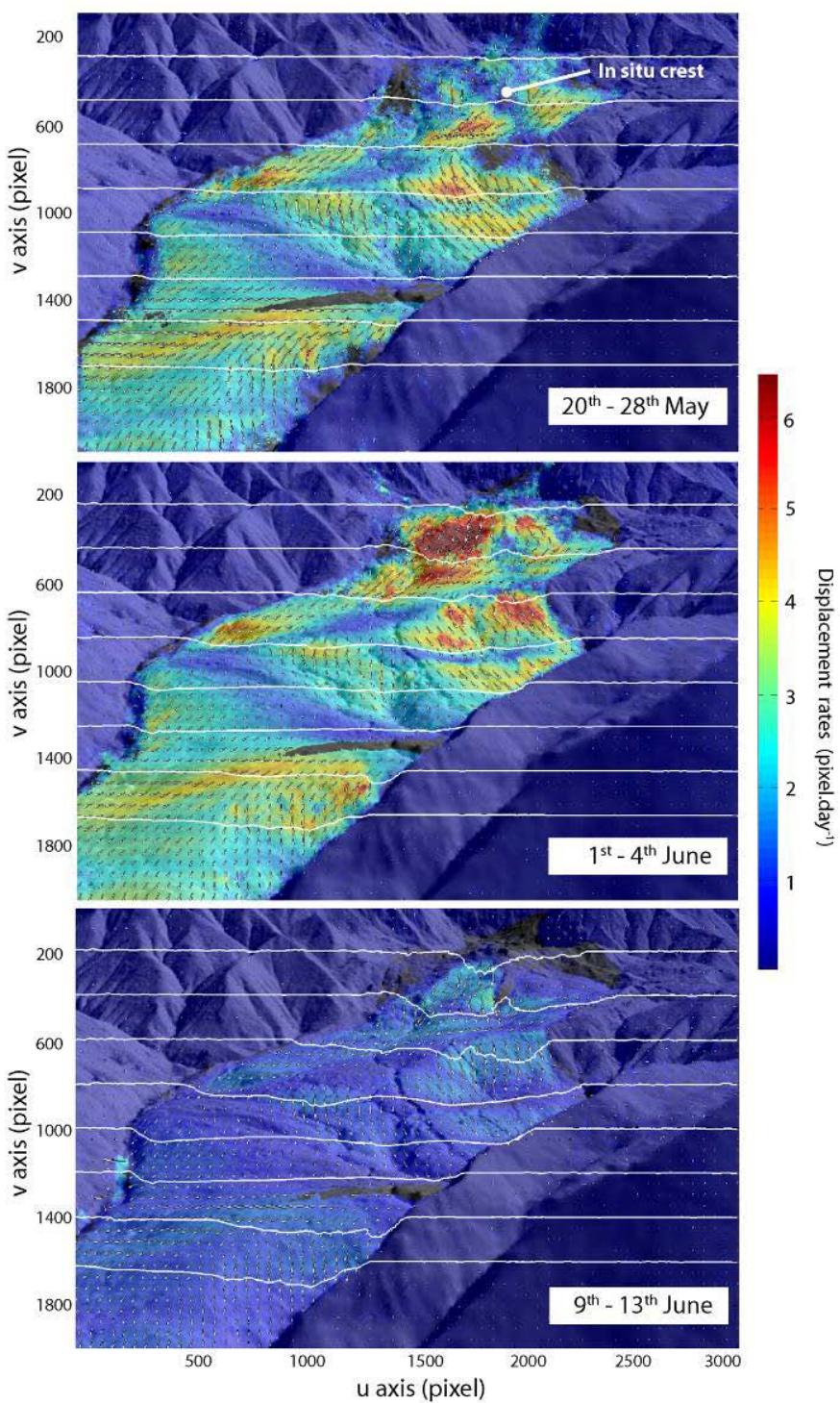

Figure 3 Displacement rates amplitude (color) and direction (arrows) in the image plane and cumulated displacements along eight profiles crossing the landslide over the period 20 May25 June 2008. In order to highlight the displacement direction, the arrow length is normalized for each image.

Figure 3 shows an example of displacement rates (in pixel.day ${ }^{-1}$ ) of the ground surface in the image plane derived from image pairs of 20-28 May 2008, 1-4June 2008 and 9 June-13 June 2008. The reference is the image of 20 May 2008. The contrast in displacement rates between the landslide area and the stable area gives confidence on the calculated velocity field. One can notice that the pattern of displacement rate is heterogeneous spatially and temporally.

The upper part of the landslide displays the highest velocity ranging from 1 to 7 pixels.day ${ }^{-1}$ while the lower 
part displays velocity of less than 4 pixels.day ${ }^{-1}$. From the 20 May to the 13 June, cumulated displacements up to 110 pixels are observed in the upper part. The maximum of displacement rate is observed around the $1^{\text {st }}$ June. Then the landslide decelerates to displacement rate of about 1 pixel.day ${ }^{-1}$. No quantitative comparisons can be carried out at this stage because the pixel sizes vary strongly in the image (Fig. 4).

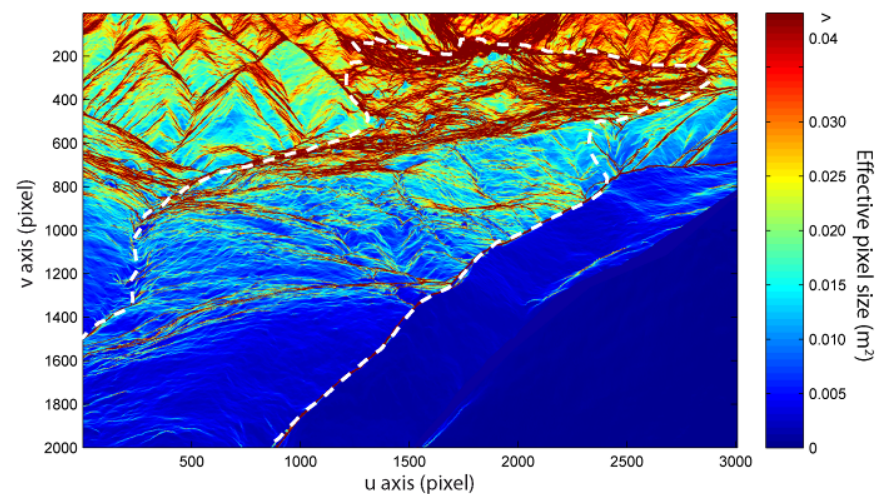

Figure 4 Effective pixel size calculated for the optical images by using an airborne laser scanning DEM acquired in 2009 and projected in the image geometry $\left(\right.$ in $\mathrm{m}^{2}$ ).

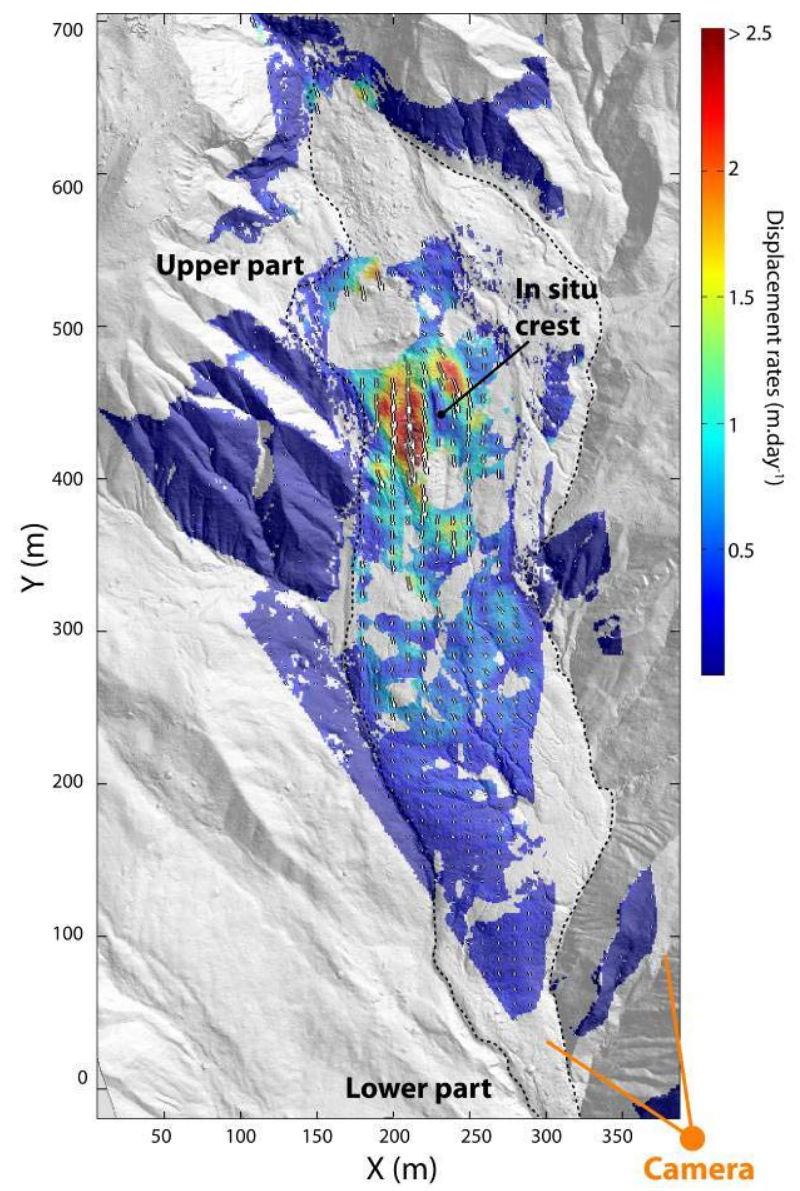

Figure 5 Displacement rates map for the period 1-4 June 2008 in the local geographic coordinate system.

The displacement fields computed in the image plane are then orthorectified in a local geographic coordinate system by transforming the central projection of the image into an orthogonal view of the ground using the collinearity equations (Kraus \& Waldhaüsel, 1994). The details of the methodology are explained in Travelletti et al. (in press). Figure 5 presents the amplitude of the $3 \mathrm{D}$ orthorectified displacement rates for the period 1-4 June. The difference of kinematics between the upper (until 3 m.day $^{-1}$ ) and the lower (until 1 m.day ${ }^{-1}$ ) parts is important The geometrical effect induced by the presence of the stable in-situ crest on the landslide kinematics is also clearly pointed out.

The precision of the computed displacements is assessed by performing a null hypothesis on the stable areas. Only the points with a correlation coefficient $r>0.8$ are taken into account. In the image plane coordinate system, the average error $\mu$ ranges from 0.5 to 0.9 pixels with standard deviation $\sigma$ of 0.3 to 1.2 pixels for the image pairs between the 20 May and the 25 June 2008. In the local coordinate system, the average error $\mu$ ranges from $0.03 \mathrm{~m}$ to $0.11 \mathrm{~m}$ with standard deviation $\sigma$ of 0.10 to 0.31 $\mathrm{m}$ for the image pairs between the 20 May and the 25 June 2008. The performance of the method has been evaluated by comparing the displacements derived from the image correlation, and the displacement monitored by dGPS on several benchmarks distributed in the stable parts and on the landslide. A correlation coefficient of $\mathrm{r}=0.95$ is found on 219 measurements and an average relative accuracy of $20 \%$ is determined (Travelletti et al., in press)

\section{Application 2: Image Correlation of terrestrial LiDAR point clouds (TLS)}

The potential of terrestrial LiDAR (TLS) for the monitoring of geomorphologic processes has been demonstrated in the last years, mainly for defining the structure of rocky slopes susceptible to rockfalls and rockslides (Abelan et al., 2009; Oppikofer et al., 2009) or characterizing the dynamics of ice glaciers (Avian et al., 2009) and landslides (Teza et al., 2008). Automatic matching algorithms applicable to TLS data have started to be developed because of their capability to fully exploit all the geometric information available in the point clouds. The approach is to find correspondences among typical features located in multi-temporal point clouds assuming that the tracked object has a constant geometry in time and/or a perfectly rigid behaviour.

Correlation techniques can be applied on repeated TLS acquisitions in order to characterize the $3 \mathrm{D}$ displacement field. The hypothesis is that for objects scanned from a unique view point, simple $2 \mathrm{D}$ correlation functions can be applied on multi-temporal point clouds and yield the same range of accuracy than complex and time-consuming $3 \mathrm{D}$ surface matching algorithms (Teza et al., 2008). The performance of the cross-correlation algorithm is tested on datasets acquired at the toe of the Super-Sauze landslide. A long-range terrestrial laser scanner Optech ILRIS-3D has been used for the monitoring (Travelletti et al., submitted). 


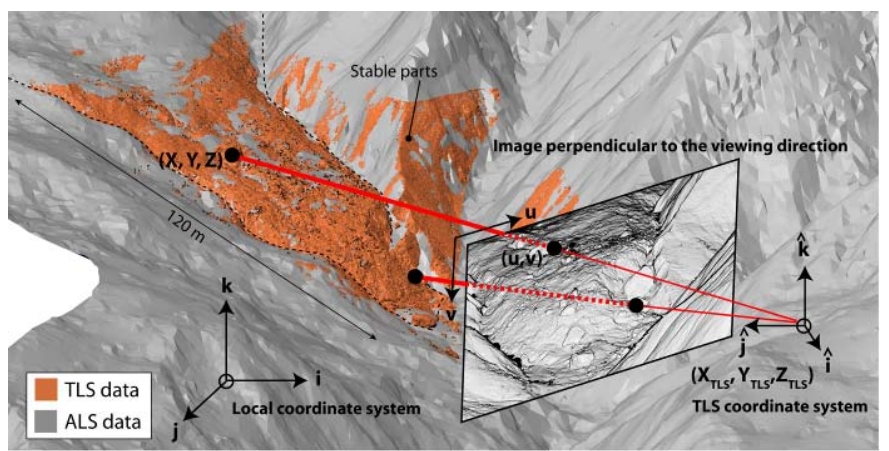

Figure 6 View of the scanned area at the Super-Sauze landslide from the TLS base station, and schematic presentation of the projective projection applied on the TLS point clouds with the different coordinate systems involved in the procedure. The alignment of the stable parts of TLS point clouds on the ALS (airborne laser scanner) point cloud is indicated.

Ten acquisitions were acquired between October 2007 and May 2010 for the same base station at an average distance of $100 \mathrm{~m}$ from the landslide toe (Fig. 6). At this distance, the laser diameter on the ground surface is estimated between 3 to $5 \mathrm{~cm}$. Only the last return pulse is registered to maximize the number of points reflected on the ground surface. The average point density at the ground surface varies from $153.0 \mathrm{pts} . \mathrm{m}^{-2}$ to $234.9 \mathrm{pts} . \mathrm{m}^{-2}$ with a standard deviation up to 351.7 pts. $\mathrm{m}^{-2}$ and a maximal density of 1148.3 pts. ${ }^{-2}$.

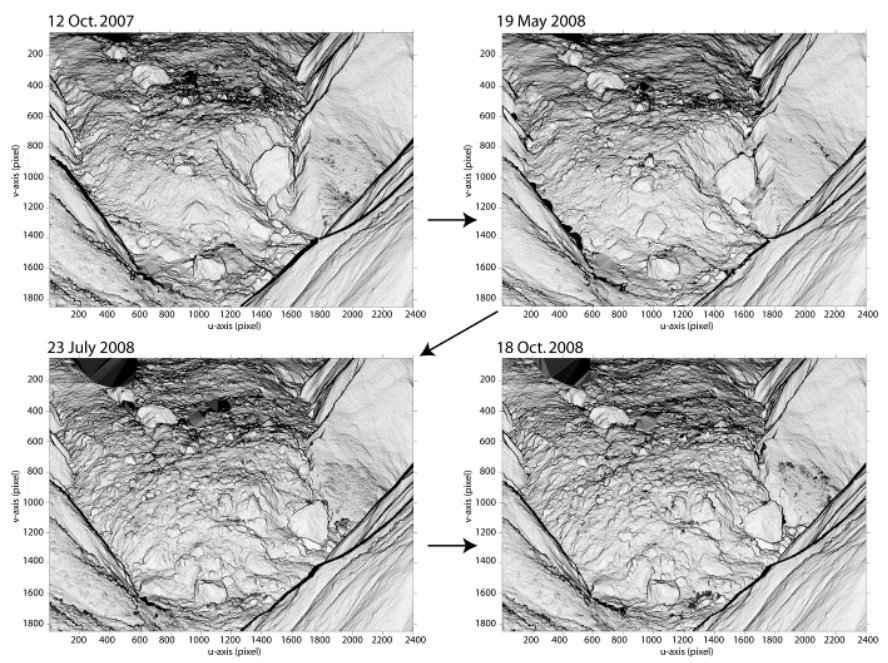

Figure 7 Images derived from the gradient calculation on the TLS point clouds for the period October 2007 - October 2008 at Super-Sauze. The morphology of the landslide toe is very well represented and the progression of the landslide toe is highlighted.

Filtering of vegetation and co-registration of the point clouds have been carried out with the software Polyworks 11 (Innovmetric, 2009). A projective transformation is used to represent the entire geometrical information in a plan perpendicular to the viewing direction of the laser scan using the collinearity equations (Kraus and Waldhaüsel, 1994). The point density varies from 0.78 to 0.94 pt.pixels $^{-1}$ with a relatively low standard deviation of $0.18 \mathrm{pt}^{\mathrm{p}} \mathrm{pixel}^{-1}$. The distance between the point clouds to the position of the laser scanner is then determined and linearly interpolated in a regular grid. Because the correlation function gives better results where the input data contains regions of rapidly varying pixel information (Duffy and Hughes-Clarke, 2005), the norm of the 2D gradient in $u$ and $v$ directions of the distance between the point clouds and the TLS station is calculated for emphasizing the morphology of the landslide. The generated images are then converted in grey-scale values (16 bits) and are used as inputs for the image correlation algorithm (Fig. 7).

The computed displacements are generally well reproduced for all periods of acquisition. Two acquisition periods (July-October 2008, July-October 2009) are presented to illustrate the performance of the approach and the behaviour of the landslide (Fig. 8). For the period July - October 2008, displacements between 0.5 and $1.5 \mathrm{~m}$ are observed, corresponding to an average displacement rate of 0.6 to $1.7 \mathrm{~cm}$.day ${ }^{-1}$. The displacement field displays significant spatial heterogeneities. The largest displacements are detected in the front of the toe where the slope gradient increases. The detachment of a toe compartment is also highlighted in the front.

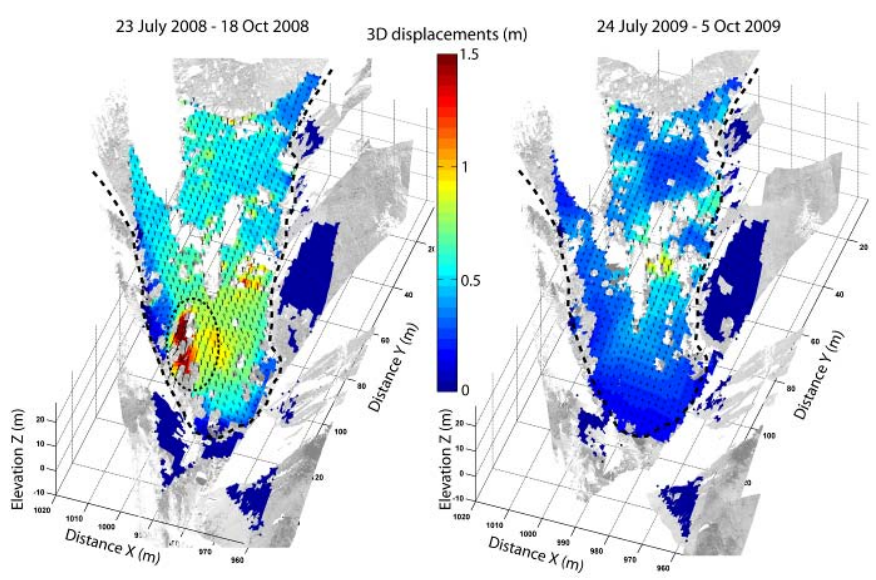

Figure 83 D displacements field obtained by TLS measurements related to the acquisition periods of July-October of the years 2008 and 2009. The dashed circle indicates the detachment of compartment at the front of the toe.

During the period July-October 2009, the landslide displays a very different kinematics both in terms of magnitude and spatial distribution. Displacements are shorter and range from $0.1 \mathrm{~m}$ at the front to $0.6 \mathrm{~m}$ in the upper part, corresponding to an average displacement rate of 0.1 to $0.8 \mathrm{~cm}$.day-1.

The computed displacements are validated by comparing the displacement values to dGPS observations of a series of blocks easily recognizable in the TLS point clouds. This comparison allows evaluating the accuracy of the approach by taking into account the noise in the data with the co-registering errors between two acquisitions. 

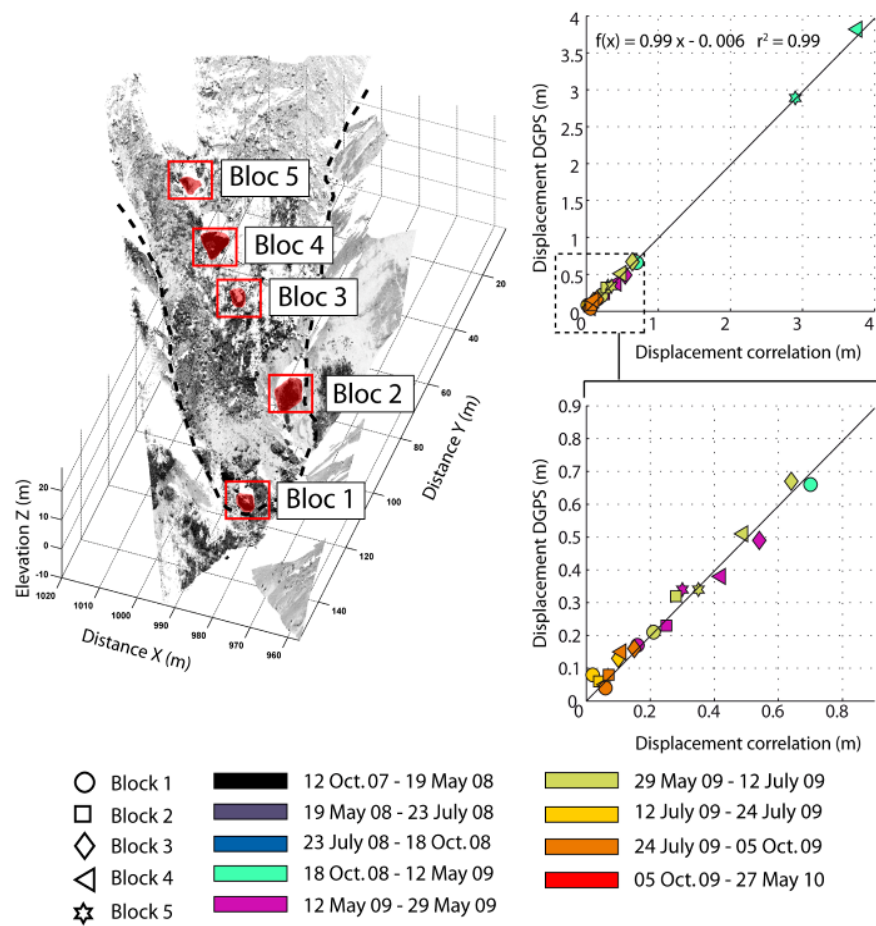

Figure 9 Comparison and validation of the displacements obtained by correlation with dDGPS observations on a series of blocks.

The displacements perfectly correlate $\left(\mathrm{r}^{2}=0.99\right)$, and a mean error and a standard deviation of $0.04 \mathrm{~m}$ and $0.03 \mathrm{~m}$ are determined (Fig. 9). This results show that the error due to the co-registering is about $3 \mathrm{~cm}$.

\section{Application 3: Image Correlation of airborne LiDAR point clouds (ALS)}

A similar approach can be used for the creation of displacements maps from repeated airborne LiDAR point clouds (ALS). In this case, the landslide of La Valette is taken as example to illustrate the potential of the technique. Two DEMs with one-metre mesh size are interpolated from airborne LiDAR data acquired in Octobre 2007 and July 2009. The average point density at the ground surface varies from $0.7 \mathrm{pts} . \mathrm{m}^{-2}$ to $7.2 \mathrm{pts} . \mathrm{m}^{-2}$ with a standard deviation up to $12.1 \mathrm{pts} . \mathrm{m}^{-2}$. Two complementary pieces of information are directly derived from the DEMs (Fig. 10):

+ the elevation differences ( $\mathrm{Z}$ component) indicating an accumulation of mass in the transit zone;

+ the horizontal displacement field (E-N components) obtained by correlating the $2 \mathrm{D}$ gradient of the topography with a size of the correlation window of 20 $\mathrm{m}$; the results indicate a decrease of the displacement magnitudes from the transit zone to the accumulation zone where nearly null displacements are observed.

The landslide behavior is controlled by a drainage system installed to stabilize the accumulation zone. Consequently, an increase of strain and an accumulation of mass occur near the Serre road demonstrating that the drainage system might not be the best solution to control the long term behavior of the slope.
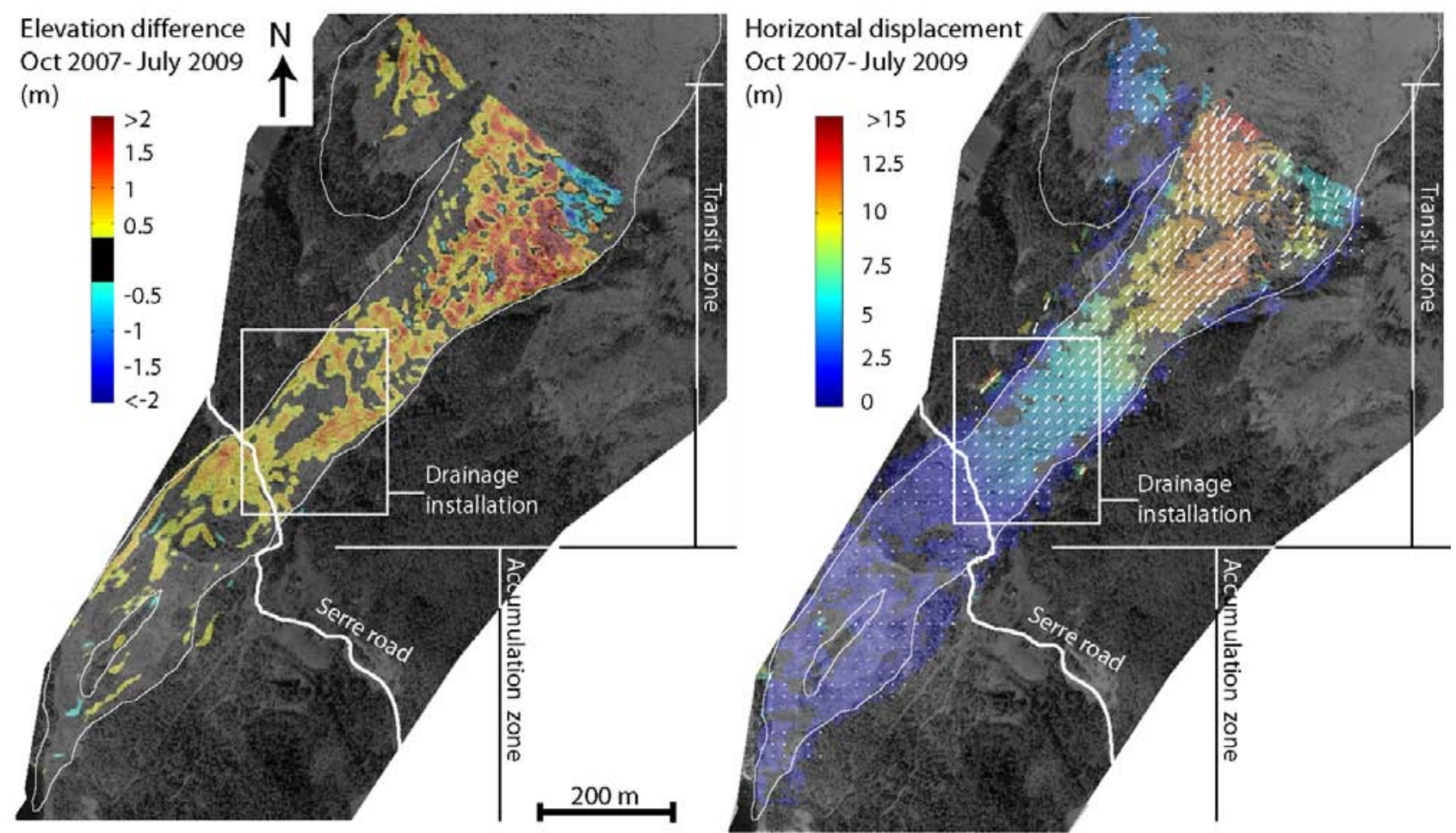

Figure 10 Displacement field calculated at the La Valette landslide from two airborne LiDAR acquisitions in October 2007 and July 2009.Left: Displacement field in the $\mathrm{Z}$ direction indicating changes in elevation, and possible zones of material accumulation or erosion. Right: Displacement field in planimetry indicating changes in distribution of mass. 


\section{Conclusion}

The potential of Image Correlation technique applied to multi-temporal terrestrial photographs or airborne or terrestrial LiDAR point clouds has been evaluated using datasets available on the Super-Sauze and La Valette landslides (South French Alps). Operational methodologies are available to compute displacement rates both in the image plane coordinate system and in local geographic coordinate systems. The technique allows to clearly characterize heterogeneous displacement field of landslides in space and in time, with a high detection thresholds $\left(\mathrm{cm} \cdot\right.$ day $\left.^{-1}\right)$. The displacements maps computed from the images are in good agreement with local information on the displacement rates observed with classical geodetic techniques such a dGPS.

Using terrestrial images, the effect of pixel size at the ground (according to the distance to the target), the incidence of the line of sight to the ground and the resolution of the image are limiting factors to detect low displacement rates. Moreover, areas of low incidence angles $\left(<5^{\circ}\right)$ are very sensitive to small movements of the acquisition platform, that can partly be corrected. Other limiting factors for optical images are related to the meteorological and illumination conditions and the ground surface changes inducing partial or complete loss of coherence between image pairs.

The results demonstrate that Image Correlation techniques implemented in permanent monitoring system are particularly interesting for monitoring landslides characterized by annual pluri-decimetric displacements. This work offers very promising perspectives for operational applications which can be potentially integrated in early warning systems by considering additional efforts in direct data transmission. Finally, inversion of the displacement field could be developed to characterize the macroscopic rheological properties of the landslide material.

\section{Acknowledgments}

This work was partly supported by the European Commission under the Marie Curie Contract 'Mountain Risks: from prediction to management and governance' (FP6, MCRTN-035798; 2007-2010), and the European Project $\mathrm{FP}_{7}$ 'SafeLand: Living with landslide risk in Europe' (2009-2012). The authors are grateful to Mr. Grzegorz Skupinski (University of Strasbourg) for his support in the acquisition of the Terrestrial Laser Scanning data.

\section{References}

Abellán, A., Jaboyedoff, M., Oppikoffer, T., Vilaplana, J. M., (2009). Detection of millimetric deformation using a terrestrial laser scanner: experiment and application to a rockfall event. Natural Hazards Earth System Sciences, 9, 365-372.

Avian, M., Kellerer-Pirklbauer, A., Bauer, A. (2009). LiDAR for monitoring mass movements in permafrost environments at the cirque Hinteres Langtal, Austria, between 2000 and 2008. Natural Hazards Earth System Sciences, 9, 1087-1094.

Casson B., Delacourt C., Allemand, P. (2005). Contribution of multitemporal sensing images to characterize landslide slip surface Application to the La Clapière Landslide (France). Natural Hazards and Earth System Sciences, 5, 425-437.

Casson, B., Baratoux, D., Delacourt, D., Allemand, P. (2003). "La Clapière" landslide motion observed from aerial differential high resolution DEM. Engineering. Geology, 68, 123-139.

Chambon, G. (2003). Caractérisation expérimentale du frottement effectif des zones de faille. PhD Thesis. Université Paris XI Orsay, ENPC.

Debella-Gilo M., Kääb, A. (2010). Sub-pixel precision image matching for measuring surface displacements on mass movements using normalized cross-correlation. Remote Sensing of Environment (2010).

Delacourt, C., Allemand P., Casson B., Vadon H. (2004). Velocity field of the "La Clapiere" landslide measured by the correlation of aerial and Quick-Bird satellite images. Geophysical. Research Letters, 31, 1-5.

Delacourt, C., Allemand, P., Berthier, E., Raucoules, D., Casson, B., Grandjean, P., Pambrun, C., Varel, E. (2007). Remote-sensing techniques for analysing landslide kinematics: a review. Bulletin de Société Géologique, 178, 89-100.

Duffy, G.P., Hughes-Clarke, J.E. (2005). Application of spatial cross correlation to detection of migration of submarine sand dunes. Journal of Geophysical Research, 110, 1-11.

El Alaoui. M.I., Ibn-Elhaj, E. (2009). A robust hierarchical motion estimation algorithm in noisy image sequences in the bispectrum domain. Signal Image and Video Processing, 3, 291302.

Foppe, K., Barth, W., \& Preis, S. (2006). Autonomous Permanent Automatic Monitoring System with Robot-Tacheometers. Proceedings of of the XXIII International FIG Congress, Munich, Germany.

Hild, F. (2003). Mesure de champs de déplacement par corrélation d'images et applications en mécanique des solides. Notes de cours IPSI. Laboratoire de Mécanique et Technologie, CNRSUMR 8535, Université Paris 6, France.

InnovMetric, (2009). PolyWorks User's Manual - 3-D scanner and 3D digitizer software from InnovMetric Software Inc., http://www.innovmetric.com/

Jaboyedoff, M., Ornstein, P., Rouiller, J.-D. (2004). Design of a geodetic database and associated tools for monitoring rockslope movements: the example of the top of Randa rockfall scar. Natural Hazards and Earth System Science, 4, 187-196.

Kraus, K., Waldhäusl, P. (1994). Photogrammetry, Fundamentals and Standard processes. vVol . 1. Hermès (editor), Paris.

Kumar, S., Banerjee, S., (1998). Development and application of a hierarchical system for digital particle image velocimetry to freesurface turbulence. Physics of Fluids, 10, 160-177.

LePrince, S., Berthier, E., Ayoub, F., Delacourt, C., \& Avouac, J.- P. (2008). Monitoring earth surface dynamics with optical imagery. Eos, 89, 1-5.

Lewis, J.P., (1995). Fast normalized cross-correlation. Vision Interface, 120-123.

Malet, J.-P., Maquaire, O., Calais, E. (2002). The use of global positioning system techniques for the continuous monitoring of landslides. Geomorphology, 43, 33-54.

Oppikofer, T., Jaboyedoff, M., Kreusen H.-R. (2008). Collapse at the eastern Eiger flank in the Swiss Alps. Nature Geoscience, 8, 531535.

Oppikofer, T., Jaboyedoff, M., Blikra, L. H, Derron, M. H., Metzger, R. (2009). Characterization and monitoring of the Aknes rockslide 
using terrestrial laser scanning. Natural Hazards and Earth System Sciences, 9, 1003-1019.

Press, W.H., Flannery, B.P., Teukolsky, S.A., Vetterling, W.T. (1997). Numerical Recipes. Cambridge University Press, New York.

Rohaly, J., Frigerio F., Hart D. P. (2002). Reverse hierarchical PIV processing. Measurement Science and Technology, 13, 984-996.

Teza, G., Pesci, A., Genevois, R., Galgaro, A. (2008). Characterization of landslide ground surface kinematics from terrestrial laser scanning and strain field computation. Geomorphology, 97, 424$-437$.

Travelletti, J., Delacourt, C., Toussaint, R., Allemand, P., Malet J.-P., Schmittbuhl, J., Bastard, M. 2011 (in press) Correlation of multitemporal ground-based images for landslide monitoring: application, potential and limitations. International Journal of Photogrametry and Remote-Sensing, 25p. (in press).

Travelletti, J., Malet J.-P., Delacourt, C., (submitted, in review). Multi-date correlation of Terrestrial Laser Scanning data for the characterization of landslide kinematics. Geomorphology, 15p. (in review). 